\title{
Solubilization of human erythrocyte membranes by ASB detergents
}

\author{
C.C. Domingues ${ }^{1}$, S.V.P. Malheiros ${ }^{1,2}$ and E. de Paula ${ }^{1}$ \\ ${ }^{1}$ Departamento de Bioquímica, Instituto de Biologia, Universidade Estadual de Campinas, Campinas, \\ SP, Brasil \\ 2Departamento de Biologia e Fisiologia, Faculdade de Medicina de Jundiaí, Jundiaí, SP, Brasil \\ Correspondence to: E. de Paula, Departamento de Bioquímica, Instituto de Biologia, UNICAMP, \\ Caixa Postal 6109, 13083-970 Campinas, SP, Brasil \\ Fax: +55-19-3521-6129. E-mail: depaula@unicamp.br
}

\begin{abstract}
Understanding the membrane solubilization process and finding effective solubilizing agents are crucial challenges in biochemical research. Here we report results on the interaction of the novel linear alkylamido propyl dimethyl amino propanosulfonate detergents, ASB-14 and ASB-16, with human erythrocyte membranes. An estimation of the critical micelle concentration of these zwitterionic detergents (ASB-14 $=100 \mu \mathrm{M}$ and ASB-16 = $10 \mu \mathrm{M}$ ) was obtained using electron paramagnetic resonance. The amount of proteins and cholesterol solubilized from erythrocytes by these detergents was then determined. The hemolytic activities of the ASB detergents were assayed and the detergent/lipid molar ratios for the onset of hemolysis $\left(R_{e}{ }^{\text {sat }}\right)$ and total lysis $\left(R_{e}{ }^{\text {sol }}\right)$ were calculated, allowing the determination of the membrane binding constants $\left(K_{b}\right)$. ASB14 presented lower membrane affinity $\left(K_{b}=7050 \mathrm{M}^{-1}\right)$ than ASB-16 $\left(\mathrm{K}_{b}=15610 \mathrm{M}^{-1}\right)$. The amount of proteins and cholesterol solubilized by both ASB detergents was higher while $R_{e}$ sat values (0.22 and 0.08 detergent/lipid for ASB-14 and ASB-16, respectively) were smaller than those observed with the classic detergents CHAPS and Triton X-100. These results reveal that, besides their well-known use as membrane protein solubilizers to enhance the resolution of two dimensional electrophoresis/ mass spectrometry, ASB-14 and ASB-16 are strong hemolytic agents. We propose that the physicochemical properties of ASB detergents determine their membrane disruption efficiency and can help to explain the improvement in the solubilization of membrane proteins, as reported in the literature.
\end{abstract}

Key words: Hemolysis; Protein solubilization; Erythrocyte; Zwitterionic detergents; Critical micelle concentration; Cholesterol solubilization

Research supported by FAPESP (\#03/02394-4). C.C. Domingues was the recipient of fellowships from CAPES (Master program) and CNPq (\#141618/2005-1).

Received March 4, 2008. Accepted August 25, 2008

\section{Introduction}

The solubilization of biological membranes by detergents has been investigated for many years (1-6). Detergents are amphiphilic compounds that solubilize membrane proteins and lipids, leading to disruption of cell membranes at high enough concentrations. According to their physicochemical properties - such as charge, critical micelle concentration (CMC), aggregation number and hydrophilic-lipophilic balance (HLB) - different interactions occur and membrane proteins are denatured or not $(4,7)$. As for the lipids, quantitative studies of membrane solubi- lization show a strong correlation between these physicochemical properties of detergents $(2,8-10)$ and their lytic effect.

In the last decades, new detergents have appeared, being designed to improve the solubilization of membrane proteins. The zwitterionic amidosulfobetaine detergents ASB-14 and ASB-16 (linear alkylamido propyl dimethyl amino propanosulfonates) with 14 and 16 atoms of carbon in the acyl chain, respectively, were synthesized by Chevallet et al. (11). They have contributed to the advance of two-dimensional gel electrophoresis analysis, improving the solubilization of many hydrophobic proteins such 
as erythrocyte band III $(12,13)$ and others $(11,14-16)$.

Despite the contribution of ASB detergents to the proteomic sciences, their role in the membrane solubilization process still remains unclear. In the present article, we studied the interaction of ASB-14 and ASB-16 with human erythrocyte membranes, using the quantitative approach described by Lichtenberg (2) to describe cell disruption and membrane solubilization.

\section{Material and Methods}

The alkylamido propyl dimethyl amino propanosulfonate detergents ASB-14 and ASB-16 were obtained from Calbiochem (USA). CHAPS and 5-doxyl stearic acid (5-SASL) were purchased from Sigma Chemical Co. (USA). All other reagents were of analytical grade.

\section{Determination of critical micelle concentration}

5-SASL films were prepared by evaporating stock chloroform solution of the spin label, under a stream of $\mathrm{N}_{2}$. PBS (147 mM NaCl, 5 mM phosphate buffer, pH 7.4) was added and the samples were vortexed for about $5 \mathrm{~min}$. Aliquots of ASB-14 or ASB-16, prepared in PBS, were added to the tubes to produce 1-5000 $\mu \mathrm{M}$ of each detergent and $50 \mu \mathrm{M}$ of 5 -SASL. Electron paramagnetic resonance (EPR) spectra were recorded in 0.2-mL flat quartz cells, at room temperature, in a Bruker EMS spectrometer, operating at $9 \mathrm{GHz}$ and $3.4 \mathrm{kG}$.

\section{Isotonic hemolytic assay}

Freshly obtained human blood from healthy donors was collected into a stock solution containing $26.3 \mathrm{~g} / \mathrm{L}$ trisodic citrate, $3.27 \mathrm{~g} / \mathrm{L}$ citric acid, $31.9 \mathrm{~g} / \mathrm{L}$ dextrose, $2.2 \mathrm{~g} /$ $\mathrm{L}$ sodium phosphate, and $0.275 \mathrm{~g} / \mathrm{L}$ adenine, and the cell were washed three times in 5 mM PBS buffer, $\mathrm{pH} 7.4$, by centrifugation.

ASB-14 (10-100 $\mu \mathrm{M})$ or ASB-16 $(1-20 \mu \mathrm{M})$, prepared in isotonic PBS, $\mathrm{pH} 7.4$, were added to the erythrocyte suspensions (0.15-0.60\% hematocrit, diluted in PBS), and the samples were kept for $15 \mathrm{~min}$ at $37^{\circ} \mathrm{C}$. After centrifugation at $260 \mathrm{~g}$ for $3 \mathrm{~min}$, membrane disruption, reported as hemolysis percentage, was measured by the hemoglobin released in the supernatant, as described by Malheiros et al. (17). Each triplicate measurement was carried out on at least two different blood samples.

\section{Solubilization of protein and cholesterol}

Blood was collected and cells washed as described above. Packed cells suspended in PBS were filtered through $\alpha$-cellulose/microcrystalline-cellulose. Ghost membranes were prepared by hypotonic hemolysis, resus- pending erythrocytes in lysis buffer $(5 \mathrm{mM}$ sodium phosphate, $0.5 \mathrm{mM}$ EDTA, $5 \mathrm{mM}$ diisopropyl fluorophosphate, $\mathrm{pH} 8.0$ ) at $4^{\circ} \mathrm{C}$, followed by centrifugation at $26,000 \mathrm{~g}$ for $20 \mathrm{~min}$ and repeated washings with the same buffer, according to Dodge et al. (18). Protein concentration was determined with bicinchoninic acid (Pierce Biotechnology, USA), using bovine serum albumin as standard.

Purified ghost membranes $(1 \mathrm{mg} / \mathrm{mL}$, final protein concentration) were mixed with ASB, CHAPS or Triton X-100, prepared in PBS, for $30 \mathrm{~min}$ at $37^{\circ} \mathrm{C}$. The samples were then centrifuged at $15,000 \mathrm{~g}$, for $30 \mathrm{~min}$ at room temperature and the supernatant solution was used for the measurement of solubilized protein and cholesterol. Cholesterol was measured using a colorimetric assay kit (R-Biopharm Italia srl, Italy; \#10139050035) for lutidine-dye (3,5-diacetyl1,4-dihydrolutidine), which has a stoichiometric relationship with the amount of cholesterol in the sample and is produced after enzymatic reactions catalyzed by cholesterol oxidase and catalase. Untreated samples of ghosts in PBS were used as control. Triplicate measurements on at least two different blood samples were carried out. The $100 \%$ values in Figure 2A,B correspond to the total protein and cholesterol concentrations, respectively, of the untreated ghosts in PBS.

\section{Results and Discussion}

\section{Electron paramagnetic resonance experiments and CMC} determination

Figure 1 presents the EPR spectra of 5-SASL in PBS buffer (0 ASB-14) and in the presence of increasing concentrations of ASB-14. At low ASB-14 concentrations (up to $75 \mu \mathrm{M}$ ), the isotropic 5-SASL signal refers to the probe in the aqueous phase. Once the CMC of ASB-14 is reached, the spin label increasingly enters the newly formed micelles, giving rise to: 1) spin-spin interactions (mainly visible as changes in the baseline of the spectra at 100 to $150 \mu \mathrm{M}$ ASB-14), and 2) broad lines and highly anisotropic signals of 5-SASL inside the micelles, easily observed at ASB-14 concentrations greater than $150 \mu \mathrm{M}$. In addition, the spin probe signal (area under the peaks) is increased, due to the increased solubility of 5-SASL in the micelles. We have determined the CMC of ASB-14 to be $100 \mu \mathrm{M}$, the lowest concentration of detergent in which a spectrum with motional restricted spin label was observed. Similar results were found for ASB-16, but micelle formation was registered at concentrations about 10 times lower $(C M C=$ $10 \mu \mathrm{M})$ than that of ASB-14. This is the first report in the literature of the CMC of ASB-14 and ASB-16. The values reported here, in PBS buffer, are quite reasonable compared with the CMC determined for other sulfobetaine 
zwitterionic homologues, Zwit 3-14 and Zwit 3-16, with equivalent acyl chains: $\mathrm{CMC}=121$ and $11.3 \mu \mathrm{M}$, respectively, in water (19) and 140 and $14 \mu \mathrm{M}$, respectively, in 0.1-0.2 $\mathrm{M} \mathrm{NaCl}(20)$.

HLB is a parameter frequently used to describe the physicochemical properties of non-ionic detergents. Here we have calculated HLB values for ASB-14 and ASB-16, from the ratio of mass between the hydrophilic/hydrophobic groups on the molecules, according to Griffin (21). Intermediate values (11.6 and 10.9, respectively) reveal the well-balanced amphiphile character of these detergents, the smaller HLB of ASB-16 being due to the contribution of its longer hydrophobic tail.

\section{Solubilization of membrane components}

Figure $2 \mathrm{~A}$ shows that the total amount of proteins solubilized from erythrocyte ghosts by ASB-14 and ASB16 is higher than that obtained with CHAPS or Triton X100 , even at the highest concentrations of detergents tested. This result agrees well with the two dimensional electrophoresis data in the literature that show an improvement in the resolution of many integral membrane proteins (11-16) with ASB-14 and ASB-16 compared with classic detergents such as Triton and CHAPS $(22,23)$. We have tested both detergents in the sample buffer used for twodimensional gel electrophoresis of red blood cells, and the results indicate that different proteins were solubilized by using these detergents, and therefore ASB detergents are useful to achieve a more detailed assignment of the proteins (24).

Figure 2B reports the amount of cholesterol released in the supernatant after treatment of red blood cell membranes with the detergents. It is interesting to note that, under the experimental conditions (starting material containing $1 \mathrm{mg} / \mathrm{mL}$ membrane proteins or ca. $1.3 \mathrm{mM}$ total lipids), the maximum amounts of cholesterol solubilized after treatment with ASB-14 or ASB-16 were reached when the detergent:lipid molar ratio was approximately 4:1, while for Triton $\mathrm{X}-100$ and CHAPS the ratios were higher (20:1 and 40:1, respectively), indicating that ASB detergents are stronger cholesterol solubilizers.

The higher amounts of cholesterol in the supernatant indicate that ASB detergents did not induce the formation of detergent-resistant membrane (DRM), known to be enriched in cholesterol and sphingolipids, as described for Triton X-100 (25-27), possibly explaining the improved solubilization of proteins eventually involved in DRM (Figure 2A). In addition, preliminary results from our laboratory indicate that a low buoyant density fraction in sucrose gradient was not formed when ASB detergents were used to solubilize erythrocyte membranes at low temperature

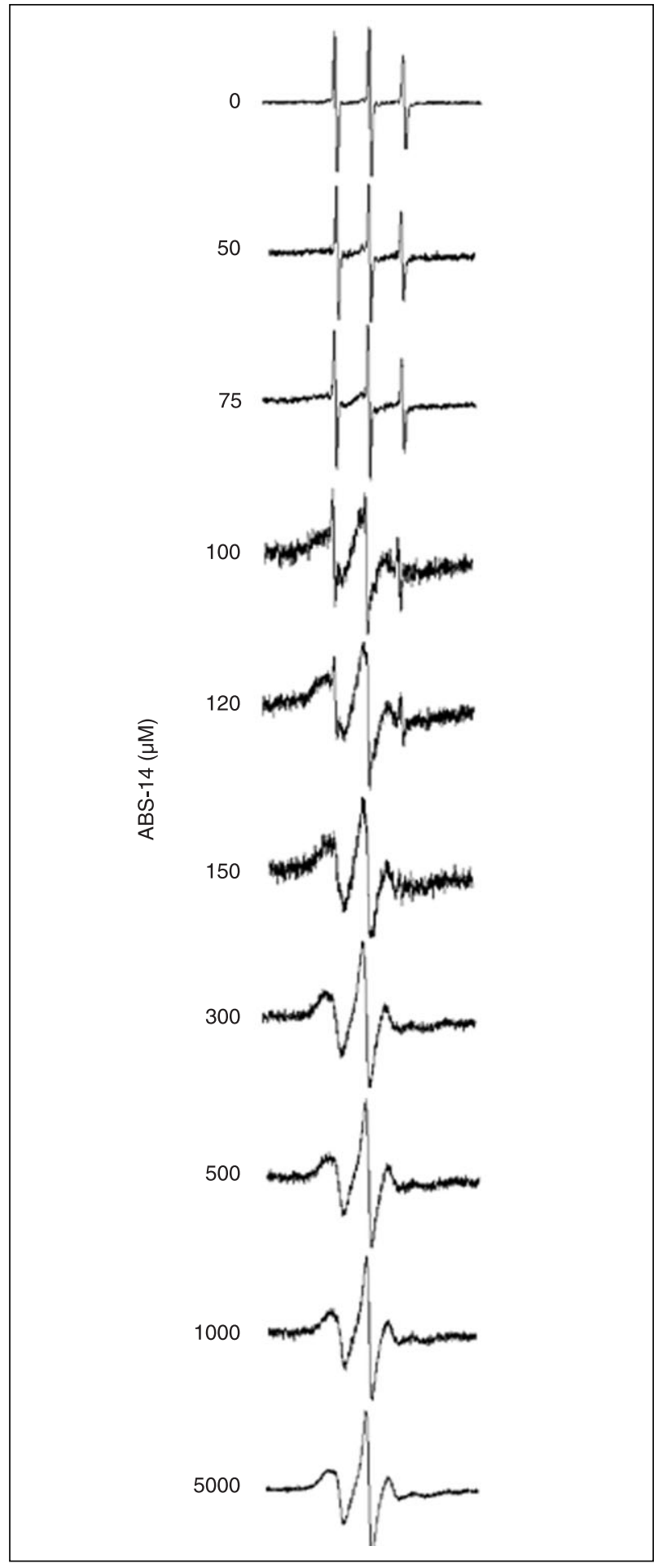

Figure 1. EPR spectra of 5-SASL in $5 \mathrm{mM}$ PBS buffer, $\mathrm{pH} 7.4$ (0 ASB-14), and in the presence of increasing ASB-14 concentrations. Line broadening and anisotropic spectra (beyond $150 \mu \mathrm{M}$ - see text) indicate the critical micelle concentration. Abscissa = 100 gauss windows around the magnetic field center (3.4 kG). 

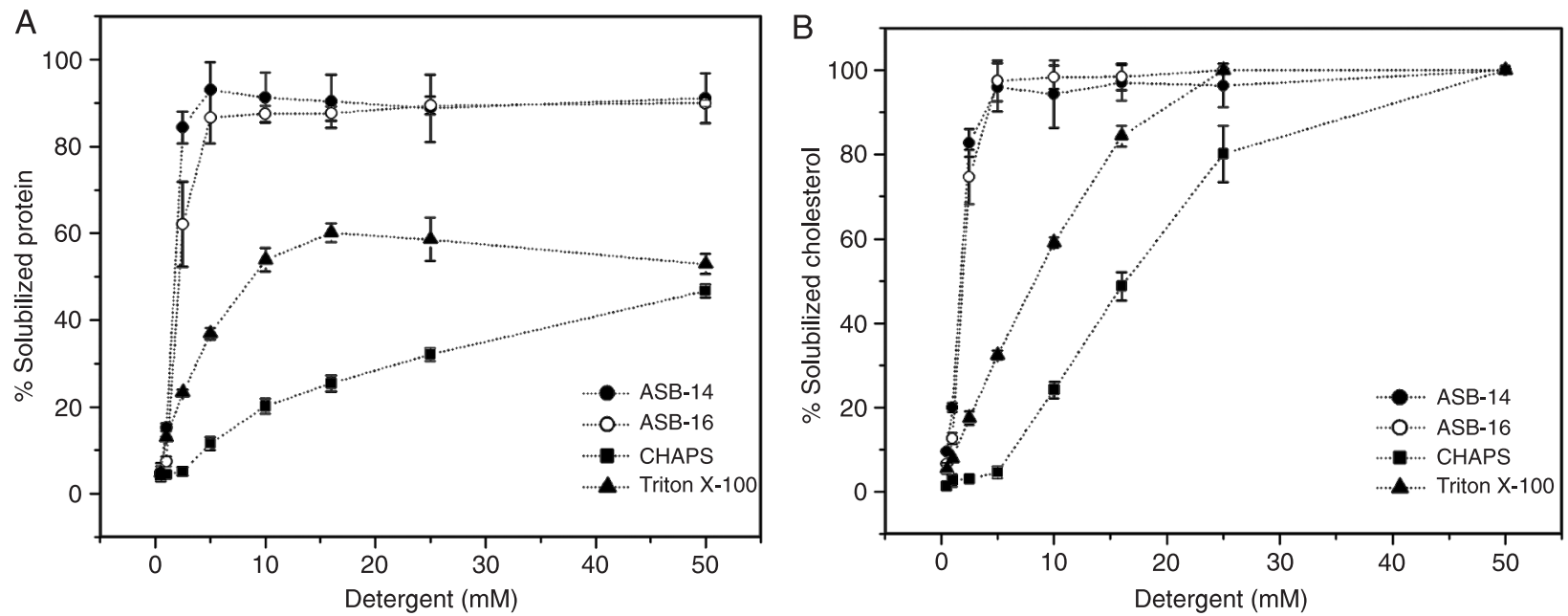

Figure 2. Protein (A) and cholesterol (B) content solubilized from erythrocyte ghosts by detergents ASB-14, ASB-16, CHAPS, and Triton $X-100$. Samples of ghosts containing $1 \mathrm{mg} / \mathrm{mL}$ of protein were incubated with the detergents in $5 \mathrm{mM} \mathrm{PBS}$ buffer for 30 min at $37^{\circ} \mathrm{C}$ and centrifuged at $15,000 \mathrm{~g}$ for $30 \mathrm{~min}$, at room temperature. Untreated samples of ghosts in PBS were used as control. The $100 \%$ values in panels A and B correspond to the total protein and cholesterol concentrations, respectively, in the untreated ghosts' samples, in PBS.
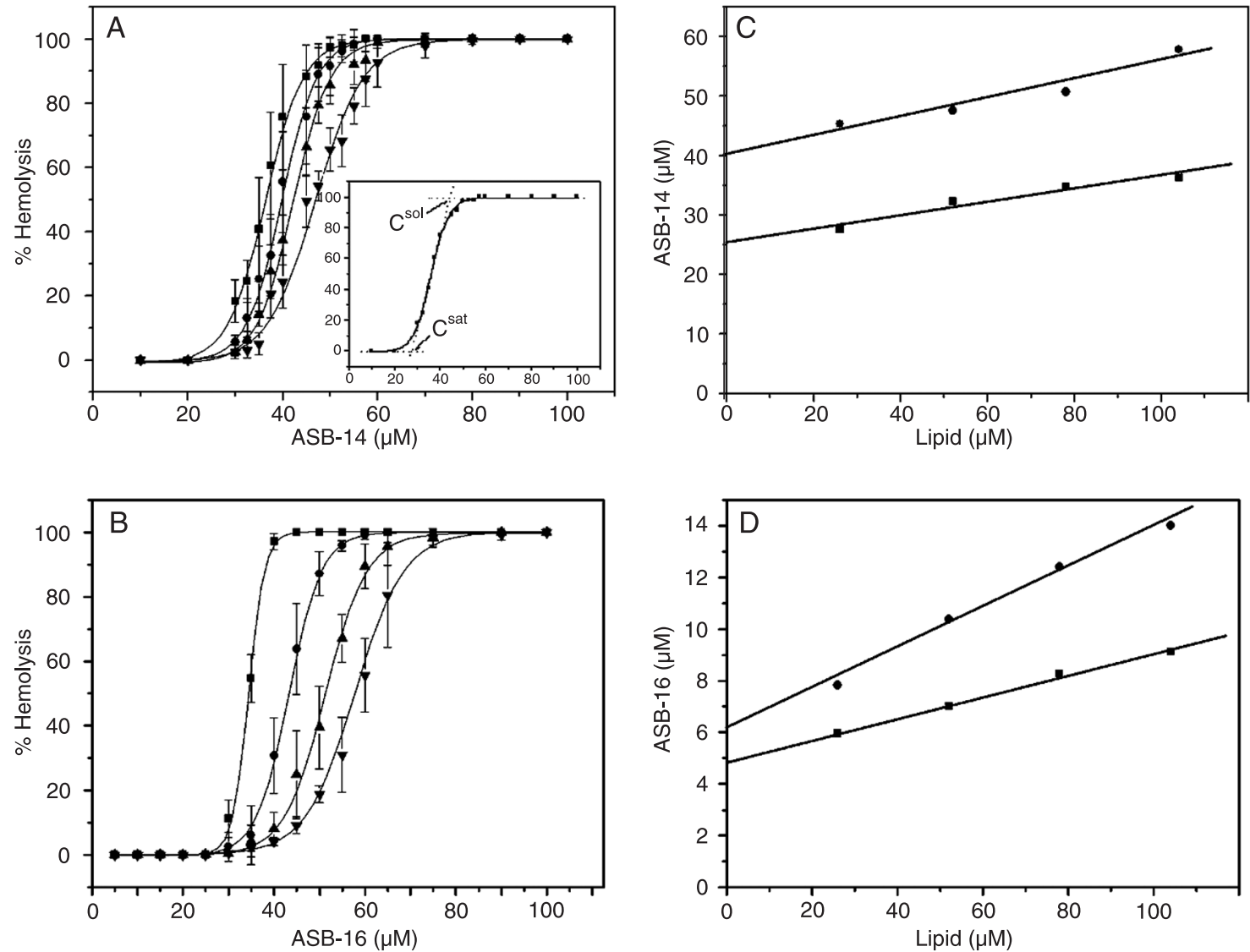

Figure 3. Hemolytic curves of ASB-14 (A) and ASB-16 (B) on human erythrocytes in $5 \mathrm{mM}$ PBS buffer, pH $7.4,37^{\circ} \mathrm{C}(15 \mathrm{~min})$ at hematocrits $0.15 \%$ (squares), $0.30 \%$ (circles), $0.45 \%$ (triangles), and $0.60 \%$ (inverted triangles). Effective detergent/lipid molar ratios for erythrocyte membranes saturation and solubilization by ASB-14 (C) and ASB-16 (D). The inset in $A$ shows the Csat and Csol determination from the hemolytic curve at $0.15 \%$ hematocrit. $C^{\text {sat }}=$ concentration required to induce membrane saturation (onset of hemolysis); $\mathrm{C}^{\text {sol }}=$ detergent concentration required for total membrane solubilization $(100 \%$ lysis $)$. 
$\left(4^{\circ} \mathrm{C}\right)$, indicating their greater power to disrupt the membrane compared with Triton X-100 (Domingues CC, Ciana A, de Paula E, Minetti $G$, unpublished results).

To further understand the membrane solubilization process, we have applied the quantitative approach proposed by Lichtenberg (2) to analyze ASB-induced erythrocyte hemolysis, as follows.

\section{Hemolytic experiments}

The hemolytic curves obtained with increasing concentrations of ASB-14 and ASB-16 in erythrocyte suspensions are shown in Figure 3A,B. Membrane disruption, reported as \% hemolysis, was determined from the amount of hemoglobin released in the supernatant solution, as previously described (17).

The quantitative analysis of the membrane solubilization process proposed by Lichtenberg (2) was applied to the hemolytic curves, considering $\mathrm{C}^{\text {sat }}$ and $\mathrm{C}^{\text {sol }}$ (inset in Figure $3 \mathrm{~A}$ ) to be the detergent concentration required to induce membrane saturation (the onset of hemolysis) and total membrane solubilization (100\% lysis), respectively $(2,6,10,17,28)$.

Plots of $\mathrm{C}^{\text {sat }}$ and $\mathrm{C}^{\text {sol }}$ as a function of membrane lipid concentration (Figure $3 C, D$ ) allowed the determination of $R_{e}$, the effective detergent/lipid molar ratio for initial $\left(R_{e}{ }^{\text {sat}}\right)$ and total hemolysis $\left(R_{e}{ }^{\text {sol }}\right)$. The straight line obtained in each case is predicted by Equation 1 $(8,9)$ :

$D_{t}=R_{e}\left[L+1 / K_{b}\left(R_{e}+1\right)\right] \quad$ (Equation 1)

where, $D_{t}$ is the total detergent concentration ( $C^{\text {sat }}, C^{\text {sol }}$ ) and $L$ is the lipid concentration in the membrane (28). $R_{e}$ values were calculated from the slope of the resulting straight lines while the $y$-intercept corresponds to $D_{w}$, the concentration of free detergent in water $(2,29) . \mathrm{K}_{\mathrm{b}}\left(\mathrm{M}^{-1}\right)$, the molar binding constant of the detergent to the erythrocyte membrane, was derived from $R_{e}$ sat and $D_{w}$ sat values, according to Equation 2 (2,29):

$R_{e}=K_{b} \cdot D_{w} /\left(1-K_{b} \cdot D_{w}\right) \quad$ (Equation 2)

Table 1 lists the $C^{\text {sat }}$ and $C^{\text {sol }}$ values obtained from the hemolytic curves of CHAPS. Prete et al. (6).
ASB-14, ASB-16 and CHAPS, a classic detergent of identical polar head group but with a steroidic hydrophobic portion (30). The small $C^{\text {sat }}$ and $C^{\text {sol }}$ values found for ASB14 and ASB-16 reflect their high capacity to solubilize erythrocyte membranes, being more potent hemolytic agents than CHAPS. The differences in $\mathrm{C}^{\text {sat }}$ and $\mathrm{C}^{\text {sol }}$ values observed between ASB-14 and ASB-16 are consistent with the results reported by Preté et al. (10) within a homologue series of detergents, in which $C^{\text {sat }}$ and $C^{\text {sol }}$ decreased with $\mathrm{C}_{\mathrm{x}} \mathrm{E}_{8}$ polyoxyethylene alkyl ethers of longer hydrocarbon chains. The smaller $C^{\text {sat }}$ and $C^{\text {sol }}$ values found for ASB-16 show that hydrophobic interactions between the detergent acyl chains and the erythrocyte membrane components are strongly involved in the solubilization process.

The hemolytic process induced by detergents could be described as a bilayer-to-micelle transition in which, according to Lichtenberg et al. (31), $R_{e}$ sat and $R_{e}$ sol determine the limits for the coexistence of mixed-membranes and

Table 1. Hemolytic effect on human erythrocytes induced by ASB-14, ASB-16 and

\begin{tabular}{|c|c|c|c|c|c|c|}
\hline \multirow[t]{2}{*}{$\mathrm{Ht}(\mathrm{L})$} & \multicolumn{3}{|c|}{$C^{\text {sat }}$} & \multicolumn{3}{|c|}{$\mathrm{Csol}^{\text {sol }}$} \\
\hline & $\begin{array}{c}\text { ASB-14 } \\
(\mu \mathrm{M})\end{array}$ & $\begin{array}{c}\text { ASB-16 } \\
(\mu \mathrm{M})\end{array}$ & $\begin{array}{c}\text { CHAPS } \\
(\mathrm{mM})\end{array}$ & $\begin{array}{c}\text { ASB-14 } \\
(\mu \mathrm{M})\end{array}$ & $\begin{array}{c}\text { ASB-16 } \\
(\mu \mathrm{M})\end{array}$ & $\begin{array}{c}\text { CHAPS } \\
(\mathrm{mM})\end{array}$ \\
\hline $0.15 \%(13 \mu \mathrm{M})$ & 27.6 & 6.0 & 4.3 & 45.3 & 7.8 & 7.4 \\
\hline $0.30 \%(26 \mu \mathrm{M})$ & 32.3 & 7.0 & 5.6 & 47.6 & 10.4 & 8.4 \\
\hline $0.45 \%(39 \mu \mathrm{M})$ & 34.7 & 8.3 & 5.8 & 50.7 & 12.4 & 8.7 \\
\hline $0.60 \%(52 \mu \mathrm{M})$ & 36.3 & 9.1 & 6.0 & 57.9 & 14.0 & 9.2 \\
\hline
\end{tabular}

Experimental condition as in Figure 3. $\mathrm{L}=$ lipid concentration in erythrocyte membranes corresponding to each hematocrit $(\mathrm{Ht})$, calculated according to Malheiros et al. (28). $\mathrm{C}^{\text {sat }}=$ concentration required to induce membrane saturation (onset of hemolysis); $\mathrm{C}^{\text {sol }}$ $=$ detergent concentration required for total membrane solubilization ( $100 \%$ lysis).

Table 2. Effective detergent/lipid molar ratios and related parameters in the hemolysis of erythrocytes by ASB-14, ASB-16, CHAPS, and Triton X-100.

\begin{tabular}{lcccc}
\hline & ASB-14 & ASB-16 & CHAPS & Triton X-100 \\
\hline $\mathrm{R}_{\mathrm{e}}$ sat & 0.22 & 0.08 & 40.62 & 1.58 \\
$\mathrm{R}_{\mathrm{e}}$ sol & 0.31 & 0.16 & 43.77 & 2.15 \\
$\mathrm{D}_{\mathrm{w}}$ sat & $25.6 \mu \mathrm{M}$ & $4.9 \mu \mathrm{M}$ & $4.1 \mathrm{mM}$ & $0.10 \mathrm{mM}$ \\
$\mathrm{D}_{\mathrm{w}}$ sol & $40.2 \mu \mathrm{M}$ & $6.0 \mu \mathrm{M}$ & $7.0 \mathrm{mM}$ & $0.18 \mathrm{mM}$ \\
$\mathrm{K}_{\mathrm{b}}\left(\mathrm{M}^{-1}\right)^{\mathrm{a}}$ & 7050 & 15610 & 236 & 5900 \\
\hline
\end{tabular}

Experimental conditions as in Figure 3. $\mathrm{R}_{\mathrm{e}}$ sat $=$ detergent/lipid molar ratio for the onset of hemolysis; $R_{e}{ }^{\text {sol }}=$ detergent/lipid molar ratio for the total lysis; $D_{w}{ }^{\text {sat }}=$ concentration of free detergent in water at the onset of hemolysis; $D_{w}$ sol = concentration of free detergent in water at total lysis; $\mathrm{K}_{\mathrm{b}}=$ molar binding constant of the detergent to the erythrocyte membrane. ${ }^{a}$ Taken from the saturation curves in Figure 3C,D. bData from 
mixed-micelles. Table 2 reports the quantitative parameters calculated from the hemolytic curves in Figure 3C,D. The $R_{e}$ values smaller than unit determined for ASB-14 and ASB-16 (Table 2) confirm that these detergents present stronger lytic effects than CHAPS $\left(R_{e}=40.62\right.$; Table 2$)$ or the non-ionic Triton X-100 $\left(R_{e}=1.58\right.$; Ref. 6). In fact, the $R_{e}$ values herein described for the ASB detergents are similar to those reported by Preté et al. (10) for alkyl ether $\left(C_{x} E_{8}\right)$ homologues of equivalent acyl chains, but higher HLB.

The binding constants of ASB-14 (7050 M-1) and ASB$16\left(15610 \mathrm{M}^{-1}\right)$ in Table 2 show the different affinities of these detergents to the erythrocyte membrane, explaining their distinct lytic effects (ASB-16 > ASB-14). These results are in good agreement with those previously reported for the $C_{x} E_{8}$ homologues (10), when a straight relationship between the $K_{b}$ value and lytic effect was observed.

Moreover, the CMC values found for ASB-14 and ASB16 disclosed the correlation between the solubilization and the aggregative properties of these detergents $(1,4,5,32)$. Lichtenberg et al. (31) demonstrated that $D_{w}$ values, the concentration of free detergent in water, are related but always smaller than the CMC values, since the membrane lipids offer an additional driving force for detergent aggregation, decreasing the concentration for micelle formation. By the same reasoning, to have an estimation of the $\mathrm{CMC}$, the values of $D_{w}$ sat are preferable to those of $D_{w}$ sol, which may be influenced by the mixed micelles formed at higher detergent concentrations (33). Thus, the $D_{w}$ values found for ASB-14 and ASB-16 (25.6 and $4.9 \mu \mathrm{M}$, respectively; Table 2), are consistent with the $\mathrm{CMC}$ values determined from the EPR data. The determined $D_{w}$ value for CHAPS (4.14 mM) was also smaller than its CMC (6-10 mM; Ref. 34).

\section{References}

1. Helenius A, Simons K. Solubilization of membranes by detergents. Biochim Biophys Acta 1975; 415: 29-79.

2. Lichtenberg D. Characterization of the solubilization of lipid bilayers by surfactants. Biochim Biophys Acta 1985; 821: 470-478.

3. Lasch J. Interaction of detergents with lipid vesicles. Biochim Biophys Acta 1995; 1241: 269-292.

4. Jones MN. Surfactants in membrane solubilisation. Int $J$ Pharm 1999; 177: 137-159.

5. Schreier S, Malheiros SV, de Paula E. Surface active drugs: self-association and interaction with membranes and surfactants. Physicochemical and biological aspects. Biochim Biophys Acta 2000; 1508: 210-234.

6. Prete PS, Malheiros SV, Meirelles NC, de Paula E. Quantitative assessment of human erythrocyte membrane solubilization by Triton X-100. Biophys Chem 2002; 97: 1-5.
According to Heerklotz and Seelig (33), the membrane disruption potency of detergents can be assessed by the relationship between their $\mathrm{CMC}$ and binding constants, in which strong detergents $\left(\mathrm{K}_{\mathrm{b}} \times \mathrm{CMC}<1\right)$ are able to solubilize lipid membranes at detergent-to-lipid molar ratios smaller than 1 . Thus, by applying the product $\mathrm{K}_{\mathrm{b}} \times \mathrm{CMC}$ to classify detergents according to their membrane disruption potency (33), ASB-14 and ASB-16 can be designated as strong detergents, and their $R_{e}$ values (Table 2) smaller than 1 corroborate this classification.

This research shows that ASB-14 and ASB-16 present a high affinity to the erythrocyte membrane, being a useful tool for the solubilization of its components (both proteins and lipids), compared to classic detergents such as CHAPS or Triton $\mathrm{X}-100$. Our results suggest that the relationship between membrane disruption efficiency (Table 2) and the physicochemical properties of ASB detergents (CMC, HLB) can explain the improvement in the solubilization of membrane proteins, as described in proteomic research papers $(11-16,22,23)$

To further understand their role in the specific solubilization of membrane proteins and lipids, other experiments are being conducted by our group to evaluate the effect of ASB-14 and ASB-16 on the formation/disruption of DRM from erythrocyte membranes, using specific lipid raft markers.

\section{Acknowledgments}

We thank Dr. S. Schreier for the use of the EPR facilities and Dr. G. Minetti for kindly supplying the kits used for cholesterol and protein measurement.
7. le Maire M, Champeil P, Moller JV. Interaction of membrane proteins and lipids with solubilizing detergents. Biochim Biophys Acta 2000; 1508: 86-111.

8. Partearroyo MA, Urbaneja MA, Goni FM. Effective detergent/lipid ratios in the solubilization of phosphatidylcholine vesicles by Triton X-100. FEBS Lett 1992; 302: 138-140.

9. Requero MA, Goni FM, Alonso A. The membrane-perturbing properties of palmitoyl-coenzyme $A$ and palmitoylcarnitine. A comparative study. Biochemistry 1995; 34: 1040010405.

10. Prete PS, Gomes K, Malheiros SV, Meirelles NC, de Paula E. Solubilization of human erythrocyte membranes by nonionic surfactants of the polyoxyethylene alkyl ethers series. Biophys Chem 2002; 97: 45-54.

11. Chevallet M, Santoni V, Poinas A, Rouquie D, Fuchs A, Kieffer $S$, et al. New zwitterionic detergents improve the 
analysis of membrane proteins by two-dimensional electrophoresis. Electrophoresis 1998; 19: 1901-1909.

12. Rabilloud T, Blisnick T, Heller M, Luche $S$, Aebersold R, Lunardi $\mathrm{J}$, et al. Analysis of membrane proteins by twodimensional electrophoresis: comparison of the proteins extracted from normal or Plasmodium falciparum-infected erythrocyte ghosts. Electrophoresis 1999; 20: 3603-3610.

13. Starita-Geribaldi M, Thebault $P$, Taffin de Givenchy E, Guittard F, Geribaldi S. 2-DE using hemi-fluorinated surfactants. Electrophoresis 2007; 28: 2489-2497.

14. Molloy MP, Herbert BR, Williams KL, Gooley AA. Extraction of Escherichia coli proteins with organic solvents prior to two-dimensional electrophoresis. Electrophoresis 1999; 20: 701-704.

15. Henningsen R, Gale BL, Straub KM, DeNagel DC. Application of zwitterionic detergents to the solubilization of integral membrane proteins for two-dimensional gel electrophoresis and mass spectrometry. Proteomics 2002; 2: 1479-1488.

16. He J, Liu Y, He S, Wang Q, Pu H, Ji J. Proteomic analysis of a membrane skeleton fraction from human liver. J Proteome Res 2007; 6: 3509-3518.

17. Malheiros SV, de Paula E, Meirelles NC. Contribution of trifluoperazine/lipid ratio and drug ionization to hemolysis. Biochim Biophys Acta 1998; 1373: 332-340.

18. Dodge JT, Mitchell C, Hanahan DJ. The preparation and chemical characteristics of hemoglobin-free ghosts of human erythrocytes. Arch Biochem Biophys 1963; 100: 119130.

19. Walter A, Kuehl G, Barnes K, VanderWaerdt G. The vesicleto-micelle transition of phosphatidylcholine vesicles induced by nonionic detergents: effects of sodium chloride, sucrose and urea. Biochim Biophys Acta 2000; 1508: 20-33.

20. Brito RM, Vaz WL. Determination of the critical micelle concentration of surfactants using the fluorescent probe $\mathrm{N}$ phenyl-1-naphthylamine. Anal Biochem 1986; 152: 250-255.

21. Griffin WC. Classification of surface-active agents by HLB. J Soc Cosmet Chem 1949; 1: 311-326.

22. Martins D, Oliveira BM, Farias AS, Horiuchi RSO, Domingues CC, de Paula E, et al. The use of ASB-14 in combination with CHAPS is the best for solubilization of human brain proteins for two-dimensional gel electrophoresis. Brief Funct Genomic Proteomic 2007; 6: 70-75.
23. Di Ciero L, Bellato CM, Meinhardt LW, Ferrari F, Castellari $\mathrm{RR}$, Marangoni S, et al. Assessment of four different detergents used to extract membrane proteins from Xylella fastidiosa by two-dimensional electrophoresis. Braz J Microbiol 2004; 35: 269-274.

24. Domingues CC, Cunha ES, Winck FV, Malheiros SVP, de Paula E. Avaliação de detergentes na solubilização de proteínas de membrana eritrocitária humana em eletroforese bidimensional. Rev Ciências Biol Saúde 2007; 2: 38-46.

25. Pike LJ. Lipid rafts: heterogeneity on the high seas. Biochem J 2004; 378: 281-292.

26. Ciana A, Balduini C, Minetti G. Detergent-resistant membranes in human erythrocytes and their connection to the membrane-skeleton. J Biosci 2005; 30: 317-328.

27. Kamata K, Manno S, Ozaki M, Takakuwa Y. Functional evidence for presence of lipid rafts in erythrocyte membranes: Gsalpha in rafts is essential for signal transduction. Am J Hematol 2008; 83: 371-375.

28. Malheiros SV, Meirelles NC, de Paula E. Pathways involved in trifluoperazine-, dibucaine- and praziquantel-induced hemolysis. Biophys Chem 2000; 83: 89-100.

29. Lichtenberg D. Micelles and liposomes. In: Shimitzky M (Editor), Book review: Biomembranes. Physical aspects. Weinheim: VCH; 1993. p 63-96.

30. Attwood D, Florence AT. Surfactant systems: Their chemistry, pharmacy and biology. 2nd edn. London: Chapman and Hall; 1983.

31. Lichtenberg D, Opatowski E, Kozlov MM. Phase boundaries in mixtures of membrane-forming amphiphiles and micelle-forming amphiphiles. Biochim Biophys Acta 2000; 1508: 1-19.

32. Tragner D, Csordas A. Biphasic interaction of Triton detergents with the erythrocyte membrane. Biochem J 1987; 244: 605-609.

33. Heerklotz H, Seelig J. Correlation of membrane/water partition coefficients of detergents with the critical micelle concentration. Biophys J 2000; 78: 2435-2440.

34. Chattopadhyay A, Harikumar KG. Dependence of critical micelle concentration of a zwitterionic detergent on ionic strength: implications in receptor solubilization. FEBS Lett 1996; 391: 199-202. 